\title{
A importância da poesia no desenvolvimento psíquico do estudante de nível médio
}

The importance of poetry in the psychic development of the high school student

Fabíola FERNANDES ANDRADE*

RESUMO: Este artigo tem como objetivo refletir sobre a importância da poesia no desenvolvimento psíquico superior dos estudantes do ensino médio. Por meio de um levantamento bibliográfico é realizada uma reflexão sobre a importância do professor como mediador no processo de ensinoaprendizagem e como a poesia é uma ferramenta importante para o desenvolvimento do estudante. As reflexões são norteadas por Calkins (1989), Bakhtin(2014), Leontiev(2014), Luria(1979,1996), Perrotti(1986) e Vygotsky (2007,2010). Posteriormente, é apresentada uma experiência em sala de aula do curso técnico de Eletroeletrônica do IFCE. Os estudantes sentiram-se motivados para a escrita de um discurso polifônico, aberto e multidirecionado que é a poesia. Compartilharam suas experiências, sentimentos e valores.

PALAVRAS-CHAVE: Ensino Médio; Poesia; Mediação

\begin{abstract}
This article aims to reflect on the importance of poetry in the higher psychic development of High School students. Through a bibliographical survey a reflection is made on the importance of the teacher as mediator in the teaching-learning process and how poetry is an important tool for student development. The reflections are guided by Calkins (1989), Bakhtin (2014), Leontiev (2014), Luria $(1979,1996)$, Perrotti (1986) and Vygotsky (2007,2010). Subsequently, a classroom experience at the IFCE Electrotechnology technical course is presented. The students felt motivated for the writing of a polyphonic, open and multidirectional speech that poetry is. They shared their experiences, feelings and values.
\end{abstract}

KEYWORDS: High School, Poetry, Mediation

\section{Introdução}

Este artigo utiliza-se do conceito de Vygotsky (2010) sobre a importância dos signos como instrumento psicológico para o desenvolvimento do estudante. Segundo o autor, a vivência do discente com a poesia serve para aprimorá-lo na formação de conceitos, uma vez que a linguagem poética não é apenas um meio de comunicação, “[...] mas também o veículo mais importante do pensamento, que assegura a transição do sensorial ao racional na representação do mundo." (LURIA, 1979, p.81). A poesia nutre sentimentos e conceitos que auxiliam no desenvolvimento dos processos psíquicos.

A literatura transforma a linguagem verbal em uma obra de arte, com discurso rico e complexo. Os signos são escolhidos, refletidos e planejados pelo autor para despertar a sensibilidade e os valores estéticos do leitor. Nesse sentido, a poesia, um dos gêneros literários, apresenta um discurso polifônico, aberto e multidirecionado, desenvolvendo a imaginação e a criatividade do leitor (PERROTTI, 1986). Isso resulta em "efeitos secundários 
muito mais eficazes que a linguagem didática" (PERROTTI, 1986, p.63), pois no discurso didático, de natureza utilitária, a linguagem pretende ser unidirecional, monofônica, com relação narrador-leitor de doutrinação. Portanto, o narrador é possuidor da verdade e apresenta um mundo acabado (PERROTTI, 1986).

Na poesia, o leitor é o construtor de significados, pois reflete, questiona e transforma a realidade interior e exterior. Na linguagem poética, a realidade é transformada em contemplação emocional, capaz de aprimorar as emoções, a sensibilidade e os mais profundos desejos da alma. O leitor torna-se receptivo às manifestações da beleza, realça signos e significantes. Para tanto, o autor precisa ocupar o lugar do artista que combina sons, conceitos, signos, experiências e ritmos.

Com o objetivo de motivar os estudantes na escrita, foi solicitado aos discentes do terceiro ano do curso técnico de Eletroeletrônica do Instituto Federal de Educação, Ciência e Tecnologia (IFCE) que escrevessem poesias. Eles escreveram tudo que estavam pensando e puderam se comunicar por meio da poesia. O lócus operacional foi uma sala de aula do IFCE e foi realizado no primeiro semestre de 2018.

Esta pesquisa procura identificar se há realmente melhoras no desenvolvimento do estudante ao motivá-los para a escrita de poesias que estejam relacionadas com a sua vida.

A experiência implementada no IFCE teve embasamento teórico nos seguintes autores: Bakhtin (2014), Calkins (1989), Kierkeggard (1986), Leontiev(2014), Luria (1996), Rhodes e Dudley-Marling (1996) e Vygotsky (2007)

\section{Pressupostos teóricos}

Em contexto de sala de aula, o professor deve atuar como mediador para o favorecimento de um desenvolvimento psíquico do estudante. Esse enfoque é baseado nos conceitos apresentados por Vygotsky (2007), cuja defesa tem o prisma na existência de dois tipos de mediadores: os instrumentos técnicos e os psicológicos.

Descritivamente, os instrumentos técnicos são elementos concretos, os quais o indivíduo utiliza para transformar o seu meio ou modificar a sua atividade externa. Exemplos de mediadores instrumentais concretos que o homem utiliza no seu dia a dia são os talheres (garfo e faca). Cabe aqui uma reflexão: ainda que seja possível ao homem prescindir desses instrumentos e alimentar-se com a mão, a utilização desses instrumentos funciona como um diferencial do processo psíquico e da qualidade do comportamento, haja vista que, nesse caso, 
o homem processa habilidades próprias da cultura e da história da sociedade para a conquista de um objetivo. Em outras palavras, essa operação simples de levar o alimento até a boca com talheres modifica a estrutura psicológica do processo de memória para "[...] além das dimensões biológicas do sistema nervoso humano, permitindo incorporar a ele estímulos artificiais, ou autogeradores, que chamamos de signos" (VYGOTSKY, 2007, p.32). No caso em apreço, os talheres são elos intermediários.

A diferença entre alimentar-se usando somente a mão e alimentar-se com o auxílio de elos intermediários deve-se às relações estímulos-respostas. No primeiro caso, para o estímulo da fome, tem-se como resposta imediata levar o alimento até a boca com a mão. A reação à situação-problema é, portanto, direta, podendo ser representada pela fórmula simples $(E \rightarrow R)$. No segundo caso, ao utilizar talheres, existiu um elo intermediário, como um estímulo de segunda ordem (signo), colocado no interior da operação $(E \rightarrow R)$, ou seja, o processo simples é substituído por um ato complexo, mediado. É dessa forma que o homem controla o seu comportamento. "O uso de signos conduz os seres humanos a uma estrutura específica de comportamento que se destaca do desenvolvimento biológico e cria novas formas de processos psicológicos enraizados na cultura" (VYGOTSKY, 2007, p.34). No ato de o homem utilizar talheres, tem-se uma característica tipicamente humana que atua no processo psíquico superior, nesse caso, na memória.

No entanto, quando os instrumentos são psicológicos, os resultados podem ser mais complexos ainda, dado que, por meio deles, o homem modifica a si mesmo e transforma o seu entorno. Tem-se a linguagem como exemplo dessa vertente instrumental, pois ao utilizar os signos para a comunicação, o homem traz para o jogo comunicativo uma complexidade de processos psicológicos, porquanto, o uso do signo requer habilidades tipicamente humanas, desenvolvidas durante a sua evolução histórica, cultural e social.

Retomando a questão do processo de aprendizagem em sala de aula, uma pessoa mais experiente pode atuar como mediadora entre o conhecimento e o estudante, podendo ser um professor ou outro estudante, com vistas a conduzir o outro ao desenvolvimento. Em contexto de aprendizagem formal e tradicional, cabe, pois, ao professor assumir conscientemente a função de mediador da aprendizagem, segundo Vygotsky (1999), pois o "outro" colabora para o desenvolvimento das propriedades individuais e internas da personalidade da criança.

Uma atividade escolar que constantemente necessita de um mediador é a leitura de livros de literatura e a produção de textos. No caso específico, na produção de poesia. Tem-se 
o professor como mediador para motivar o estudante na produção de poesia e quando o estudante escreve, o signo atua como instrumento psicológico que age na complexidade das funções, pois desencadeia no estudante a necessidade de refletir e inferir. Em situações cujo docente não atue como mediador, as ações psíquicas dos estudantes podem não estar reguladas à proposta solicitada e não sintam a necessidade de escrever.

Considera-se que, todos os dias, o professor e o estudante compõem o entorno da sala de aula, aquele pode perfeitamente atuar diretamente no desenvolvimento das funções psíquicas superiores deste, desde que desenvolva atividades voltadas para o uso do signo linguístico, como a escrita de poesia. Assim, os estudantes vivenciam momentos de leitura e escrita em convívio social de interação, num processo que ocorre primeiramente num plano interpsíquico (plano das interações sociais), para depois, segundo Vygotsky (2007), tornar-se intrapsíquico (plano psicológico individual), caso apresente um significado e sentido para eles.

Cabe ressaltar que a interação entre os estudantes estará sempre na dependência de uma atividade que priorize as relações sociais. O professor pode conversar com os estudantes sobre a poesia escrita, com o propósito de promover uma interação entre eles na sala de aula.

No livro A formação social da mente (2007), Vygotsky dá ênfase à linguagem como principal sistema de signos. Para Vygotsky (2007) e Luria (1996), com o uso dos mediadores psicológicos, o indivíduo habilita-se a uma nova etapa do desenvolvimento humano, dado um salto que ocorre no nível das suas funções psíquicas superiores. Assim, quando o homem se apropria da linguagem, está se apropriando de um instrumento histórico, cujo significado foi atribuído pela cultura humana. A linguagem é um instrumento mediador que o homem elaborou durante a sua história, a sua experiência e o seu convívio social (LEONTIEV, 2014).

Em termos práticos, na sociedade, quando o indivíduo nasce, a linguagem já começa a fazer parte do seu dia a dia e a interferir no processo de desenvolvimento mental. Quando ele convive com pessoas mais experientes, adquire conhecimentos e os internaliza. Assim, as funções psíquicas superiores vão se desenvolvendo (VYGOTSKY, 2007).

Na relação professor-aluno-escrita, o discente é um aprendiz ativo, ou seja, é ele quem constrói e interfere no seu desenvolvimento. O professor, na condição de mediador entre o estudante e a escrita, exerce a função de atuar como instrumento psicológico para regular as ações psicológicas dos alunos para produção textual, no caso, da poesia. 
As atividades postas em prática em sala de aula, em que o professor atua como mediador, precisam ser focadas no desenvolvimento das funções psíquicas superiores dos estudantes, o que pressupõe atividades criativas que gerem novas aprendizagens e impulsionem o desenvolvimento. Pelas palavras de Vygotsky (2007, p.103), sabe-se que "[...] aprendizado não é desenvolvimento; entretanto, o aprendizado adequadamente organizado resulta em desenvolvimento que, de outra forma, seriam impossíveis de acontecer.". Sendo assim, para que o desenvolvimento do estudante se dê de forma satisfatória, o professor pode elaborar atividades em sala de aula que sejam significativas para a vida dos estudantes.

Segundo Calkins (1989, p.15), “os seres humanos sentem uma profunda necessidade de representar sua experiência neste mundo através da escrita”. É importante que a escola estimule os estudantes a escrever sobre o seu pensamento e seu sentimento, como uma forma de expressão e comunicação. Calkins reitera esse pensamento:

Escrever permite que transformemos o caos em algo bonito, permite que emolduremos momentos selecionados em nossas vidas, faz com que descubramos e celebremos os padrões que organizaram nossa existência [...]. A escrita é mais do que a vida: ela é a tomada de consciência de que estamos vivos (CALKINS, 1989, p.15).

Na mesma linha, Kierkeggard (1986) afirma que o ato de escrever permite que nos conheçamos a nós mesmos, melhor dizendo, que manifestemos nossos sentimentos contidos em nosso interior. Para o autor, escrevemos para viver e não vivemos para escrever.

Sabendo-se do potencial humano para a escrita, foi solicitado aos estudantes do terceiro ano do curso técnico em Eletroeletrônica que escrevessem poesias. A escolha do tema foi livre, eles próprios escolheram, porém, deveriam ter relação com a sua vida para que os demais colegas pudessem conhecê-lo melhor.

As poesias produzidas pelos estudantes mostraram, de fato, a razão delas próprias, sem a interferência da escolha do tema da poesia pelo outro. Em outros termos, os estudantes escreveram na folha de papel o seu pensamento e não enunciados transmitidos a eles como tema a serem desenvolvidos. Sabe-se que as palavras do produtor de texto estão recheadas das palavras do outro (BAKHTIN, 2014), porém, o sentimento imbuído na alma, de natureza essencialmente subjetiva, traz um diferencial, uma vez que todo ser humano é diferente, singular e possui a sua própria forma de pensar e olhar o mundo (CALKINS,1989).

Com o tema livre para a produção da poesia, o estudante foi estimulado ao autoconhecimento por meio da escrita. Eles tiveram a chance de terem consciência de si (CALKINS,1989). Para Rhodes e Dudley-Marling (1996, p.10), “a linguagem escrita é 
transacional no sentido de que ambos, leitores e escritores, contribuem com alguma coisa (por meio de textos) para o ato de fazer sentido" ${ }^{1}$ (tradução nossa). Assim, ao produzir uma poesia sem um tema definido pelo professor, o estudante atribui sentido ao que escreveu e o texto representam a sua vivência e a sua experiência, sendo um legado histórico de sua vida.

Para Calkins (1989), é da natureza do ser humano a necessidade de se expressar por meio da linguagem, seja escrita, oral ou gestual. A partir dessa observação, o professor pode incentivar o estudante a expressar seus sentimentos e emoções por meio da escrita, atividade que, se bem planejada, envolverá o estudante, permitindo que ele lance mão da heterogeneidade das vozes de outrem e se aprofunde no seu "eu", expressando toda a sua subjetividade por meio das representações simbólicas (BAKHTIN, 2014).

\section{Metodologia}

Seguindo a linha de pensamento apresentado por Vygotsky (2007) no sentido de servir de mediadora para o desenvolvimento dos processos psíquico dos estudantes do curso técnico de Eletroeletrônica do IFCE, solicitei aos estudantes do terceiro ano que escrevessem poesias com tema livre, na qual eles deveriam expor os seus pensamentos e sentimentos. Assim, eles puderam liberar toda a criatividade e experiência imbuídas em seu ser.

É válido destacar que, antes de se solicitar que os estudantes escrevessem poesias, houve diálogos com os discentes, com a finalidade de motivá-los para a produção da poesia. Também entreguei alguns livros que eles podiam ler em casa para compreender melhor o texto poético. No diálogo, falei da importância de escrever para o desenvolvimento da criatividade. O lócus operacional foi a sala de aula do IFCE.

Como destaque na solicitação da poesia, elas deveriam ter relação com a sua vida para que eu e os seus colegas pudessem conhecê-lo melhor e aumentar a interação em sala de aula.

A esse respeito, afirma Bakhtin (2014, p.99) "A palavra está sempre carregada de um conteúdo ou de um sentido ideológico ou vivencial. É assim que compreendemos as palavras e somente reagimos àquelas que despertam em nós ressonâncias ideológicas ou concernentes à vida." Com a escrita de texto relacionado com a sua vida, os colegas também apresentam interesse em ler. É um período para eles se conhecerem mais.

\footnotetext{
${ }^{1}$ Written language is transactive in the sense that both readers and writers contribute something (through texts) to the act of making meaning.
} 
No momento em que os estudantes estavam escrevendo, percorri toda a sala, com o olhar sempre atento para o estilo de escrita. Também realizei questionamentos que pudessem despertar ideias e sentimentos, pois segui os ensinamentos apresentados pela Calkins (2001) na ideia de servir de mediadora na motivação da escrita como algo significativo para a vida, na exposição das emoções e sentimentos embutidos na alma. Estive alerta para a orientação focada nos princípios de coesão e coerência, uma vez que somente a correção dos erros gramaticais não é suficiente para promover o aprimoramento da escrita dos estudantes (CALKINS, 2001).

A primeira poesia escrita deve ser considerada como rascunho (CALKINS, 2001). Assim, após o término, os estudantes leram para toda a sala, a fim de, conhecendo a opinião da professora e dos colegas, ter condições de aprimorar as suas ideias e escrita. "Dessa interação poderá resultar uma reelaboração do pensamento do autor, novas discussões e revisões" (DIETZSCH; SILVA, 1994, p.60).

Em resumo, com a atividade da leitura em voz alta e diálogos com os colegas, o estudante é levado a refletir sobre o texto escrito e a melhorar a escrita, até alcançar o produto final de um texto com significação. O estudante pode melhorar sem pressa o seu texto, com a convicção de que está produzindo algo que tem significado para si, ou melhor, que representa o seu pensamento em forma de símbolos. A ajuda dos colegas promove o desenvolvimento das qualidades de comunicação e expressão (CALKINS, 2001).

A produção de poesia deve ser um processo contínuo de revisitar a escrita, a sua própria autoria, de modo que a releitura e a reescrita estejam sempre presentes, se necessárias. Segundo Calkins (1989, p.191),

Os alunos são capazes de escrever esboços após esboços, mas não sabem como aumentar suas capacidades ou como selecionar o que funciona melhor em seus textos. Uma vez que não possuem um senso daquilo que faz a boa escrita, não possuem meios de evoluir enquanto escrevem.

Por isso, é primordial que os estudantes tenham um mediador na produção de poesia, papel que deve ser desempenhado pelo professor, a partir da reflexão sobre o texto em produção, a ser feita pelo estudante sob a sua orientação. Assim, pensando sobre o que escreveu, o estudante promoverá o desenvolvimento da sua consciência, do controle do discurso e dos aspectos linguísticos complexos como a poesia (CALKINS, 1989).

A experiência relatada sobre a leitura em voz alta da poesia escrita pelos discentes foi realizada durante três aulas, tempo necessário para que a poesia fosse reescrita pelos 
estudantes. Posteriormente, eles leram suas poesias com o objetivo de apresentar o produto final e socializar o seu pensamento e sentimentos. Na sequência, foi montado um varal com as poesias. A figura 01 apresenta o varal montado no laboratório de Eletroeletrônica em 08 de maio de 2018.

Figura 01- Varal de poesia montado no laboratório de Eletroeletrônica

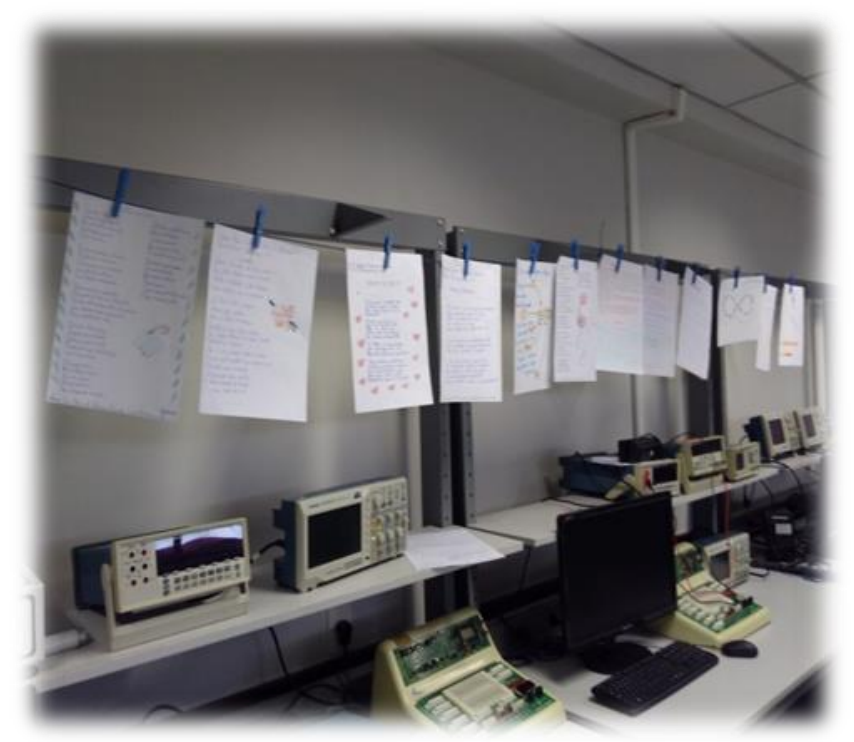

Fonte: Acervo da pesquisadora

No livro A arte de ensinar a escrever, Calkins (1989) sugere uma transformação na sala de aula, com a criação de uma comunidade de leitores-escritores. Os estudantes, ao compartilharem os seus textos, puderam vivenciar a leitura e a escrita de forma ativa, contribuindo, assim, para o desenvolvimento das funções psíquicas superiores.

\section{Resultados}

A produção de poesia pelos estudantes foi bastante enriquecedora em ambiente escolar, pois os discentes fizeram uso de um discurso complexo, rico, polifônico, aberto e multidirecionado. Pode-se perceber que eles ficaram motivados, uma vez que eles escreveram de forma descontraída e alegre, expondo o seu olhar sobre si e sobre o seu entorno. Os sentimentos e as emoções desabrocharam por meio de gestos, expressões e uso dos signos. As suas vozes foram ouvidas e refletidas ao lerem em voz alta as suas poesias para os colegas. Os seus pensamentos e valores foram socializados com a reflexão de seus textos. 
A poesia final, ao serem colocadas em um varal de poesias produziu um ambiente de ideias, imaginação e criatividade.

Ao escutar as vozes dos colegas, o estudante atribuiu sentido e significado ao texto. Houve uma interação estética entre o ouvinte e o autor. Para Miller (2013, pp.96-97) "ler e pensar em voz alta dá aos professores oportunidades para modelar os processos cognitivos usados para construir significado" 2 (tradução nossa).

$\mathrm{Na}$ função de mediadora da escrita, procurei me mostrar sensível ao que o estudante estava escrevendo, pois dialoguei com eles sobre o texto escrito, passando-lhe a certeza de estar comprometido com a sua evolução no ato de escrever (CALKINS, 2006). Nesse sentido, aproveitei todo o potencial do estudante ao atuar como mediador no desenvolvimento do processo psíquico dos discentes. As emoções e sentimentos ganharam destaques em sala de aula, pois foram expostos de forma espontânea e harmoniosa nos textos. Enfim, nesse sistema, o estudante e eu atuamos de forma ativa no processo complexo que é a aprendizagem, pois houve a necessidade de estarmos em sintonia para que os textos fossem escritos e reescritos e, apresentassem de forma coesa e coerente.

\section{Considerações finais}

A experiência relatada neste artigo apresenta a importância do professor atuar como mediador, ou seja, como um instrumento psicológico para o desenvolvimento dos processos psíquicos dos estudantes. Fato este realizado ao solicitar a escrita de uma poesia e interagir com eles durante a produção da poesia.

O objetivo primordial foi apresentar uma experiência em sala de aula que proporcionou um ambiente em que os estudantes puderam se expressar por meio da poesia para obter ganhos significativos no desenvolvimento dos processos psíquicos superiores.

É válido acrescentar que no processo de produção da poesia, o discente também dialoga consigo e este diálogo interior é "muito poderosa" na formação e complexificação dos processos psíquicos superiores (VYGOTSKY, 2012).

Sobre o discurso interior, Bakhtin (2014) afirma que:

Toda a sua atividade mental, o que se pode chamar de o "fundo perceptivo", é mediatizado para ele pelo discurso interior e é por aí que se opera a junção com o discurso apreendido do exterior. A palavra vai à palavra (BAKHTIN, 2014, p.154).

\footnotetext{
${ }^{2}$ Reading and thinking aloud gives teachers opportunities to model the cognitive processes used to construct meaning
} 
Durante a realização do ato de escrever e de ler a sua escrita de forma silenciosa, o estudante promove a ativação do processo do discurso interior. $\mathrm{O}$ fundo perceptivo assimila o enunciado obtido pelo discurso exterior (informação visual) e coteja o enunciado com a réplica interior, gerando um comentário efetivo, uma atitude responsiva (BAKHTIN, 2014). A interação entre a réplica interior e o comentário efetivo, colabora na formação do discurso interior e na consequente expressão do pensamento, levando o estudante a ampliar sua capacidade de comunicação verbal, sofisticando sua capacidade de ler, sua atitude para ler, em se fazendo aprendiz de leitura.

A prática da escrita da poesia e da leitura silenciosa são importantes para o processo de desenvolvimento do estudante, cuja capacidade de internalização proporciona uma relação com o mundo, sem a necessidade da interação concreta, independentemente das limitações temporais e espaciais. Em outras palavras, tais práticas permite que o estudante realize inferências, predições, conexões, visualizações, questionamentos, planeje, julguem, avalie, amplie o vocabulário e o conhecimento, lembre-se de algum fato, compare determinados eventos, sem a necessidade de uma vivência real (VYGOTSKY, 1999).

$\mathrm{Na}$ escrita da poesia, o estudante se isola com os seus pensamentos. No entanto, ao ler a poesia em voz alta em sala de aula, forma-se um cimento social que promove a convivência social (BAJARD, 1999), pois existe uma interação estética entre o ouvinte, o mediador e o autor. Todos se tornam ativos do processo, uma vez que também há discursões para promover uma interação com reflexões e inferências.

\section{Referências Bibliográficas}

BAKHTIN, M. Marxismo e filosofia da linguagem. 16 ed. São Paulo: Hucitec, 2014.

CALKINS, L. A arte de ensinar a escrever. Porto Alegre: Artes Médicas, 1989.

CALKINS, L. The Art of teaching reading. New York: Addison Wesley Longman, 2001.

CALKINS, L. A Guide to the Writing Workshop.Portsmouth: Firsthand, 2006.

DIETZCH, M., J, M; SILVA, M, A. S. S. Intinerantes e itinerários na busca da palavra. Cad. Pesq, São Paulo, n. 88, p.55-63, fev. 1994.

LEONTIEV, A. O desenvolvimento do Psiquismo. São Paulo: Centauro, 2014. 
LURIA, A, R. Curso de Psicologia Geral, Vol I, 2 ed. Rio de Janeiro: Civilização brasileira, 1991.

LURIA, A, R. Desenvolvimento Cognitivo, 7 ed. São Paulo: Ícone, 2013.

MILLER, D. Reading with Meaning. 2 ed, United States of America: Stenhouse Publishers, 2013.

PERROTTI, E. O texto sedutor na literatura infantil, São Paulo: Ícone, 1986.

VYGOTSKY, L, S. Pensamento e Linguagem. 2 ed. São Paulo: Martins fontes, 1999.

VYGOTSKY, L, S. A Formação social da mente. São Paulo: Martins Fontes, 2007.

VYGOTSKY, L, S. Imaginação e criatividade na infância, São Paulo: WMF Martins Fontes, 2014.

\section{Artigo recebido em: 03/03/2020 Artigo aprovado em: 04.06.2020}

